\title{
Erratum: Chén "The Roles of Statistics in Human Neuroscience", Brain Sci. 2019, 9, 194
}

\author{
Oliver Y. Chén ${ }^{1,2,3}$ [1] \\ 1 Institute of Biomedical Engineering, University of Oxford, Oxford OX1 3PJ, UK; yibing.chen@seh.ox.ac.uk \\ 2 Department of Psychology, Yale University, New Haven, CT 06510, USA \\ 3 Laboratory of Neurobiology, University College London, London WC1E 6BT, UK
}

Received: 3 March 2020; Accepted: 4 March 2020; Published: 4 March 2020

The author wishes to make an erratum to the published version of his paper [1]. In the original article, there was an error. Area V3 is specialized for dynamic form (not specialized for motion), and area V4 is specialized for color and form-with-color (not just specialized for color). A correction has been made to Section 2.2, paragraph three: "for example, area V3 is specialized for dynamic form (the shapes of objects in motion), V4 for color and form-with-color, and V5 for motion (see p. 125 in [2], p. 72 in [3], and [4])." The author apologizes for any inconvenience this may cause to all readers.

Conflicts of Interest: The author declares no competing financial interests.

\section{References}

1. Chén, O.Y. The Roles of Statistics in Human Neuroscience. Brain Sci. 2019, 9, 194. [CrossRef] [PubMed]

2. Zeki, S. A Vision of the Brain; Blackwell Scientific Publications: Oxford, UK, 1993.

3. Zeki, S. The Visual Image in Mind and Brain. Sci. Am. 1992, 267, 68-76. [CrossRef] [PubMed]

4. Zeki, S.; Chén, O.Y. The Bayesian-Laplacian brain. Eur. J. Neurosci. 2019, 1-22. [CrossRef]

(C) 2020 by the author. Licensee MDPI, Basel, Switzerland. This article is an open access article distributed under the terms and conditions of the Creative Commons Attribution (CC BY) license (http://creativecommons.org/licenses/by/4.0/). 